\title{
Downregulation of microRNA-574 in cancer stem cells causes recurrence of prostate cancer via targeting REL
}

\author{
XIAODONG LAI $^{1 *}$, YANCHUN GUO $^{2 *}$, ZHITAO GUO $^{3}$, RUIBAO LIU $^{2}$, XUNGUO WANG ${ }^{2}$ and FANG WANG ${ }^{2}$ \\ Departments of ${ }^{1}$ Urology Surgery and ${ }^{2}$ Oncology Surgery, Dongying People's Hospital, Dongying, \\ Shandong; ${ }^{3}$ Emergency Department, Tianjin Xiqing Hospital, Tianjin, P.R. China
}

Received February 25, 2016; Accepted July 5, 2016

DOI: 10.3892/or.2016.5196

\begin{abstract}
R-574-5p has been reported involved in the pathogenesis of numerous human malignancies such as colorectal and lung cancer. In this study, we aimed to explore the roles of REL and miR-574 in the recurrence of prostate cancer (PCa) and to identify the underlying molecular mechanisms. Our literature search found that miR-574 is regulated in cancer stem cells (CSCs), and next we used the microRNA (miRNA) database (www.mirdb.org) to find REL as a target of miR-574. Luciferase assay was performed to verify the miRNA/target relationship. Oligo-transfection, real-time PCR and western blot analysis were used to support the conclusions. We validated REL to be the direct gene via luciferase reporter assay system, and real-time PCR and western blot analysis were also conducted to study the mRNA and protein expression level of REL between different groups (recurrence and non-recurrence) or cells treated with scramble control, miR-574 mimics, REL siRNA and miR-574 inhibitors, indicating the negative regulatory relationship between miR-574 and REL. We also investigated the relative viability of prostate CSCs when transfected with scramble control, miR-574 mimics, REL siRNA and miR-574 inhibitors to validate miR-574 to be positively interfering with the viability of prostate CSCs. We then investigated the relative apoptosis of prostate CSCs when transfected with scramble control, miR-574 mimics, REL siRNA and miR-574 inhibitors. The results showed miR-574 inhibited apoptosis. In conclusion, miR-574 might be a novel prognostic and therapeutic target in the management of $\mathrm{PCa}$ recurrence.
\end{abstract}

Correspondence to: Dr Yanchun Guo, Department of Oncology Surgery, Dongying People's Hospital, 317 South 1st Road, Dongying, Shandong 257091, P.R. China

E-mail: prostateca@163.com

*Contributed equally

Key words: microRNA-574, cancer stem cells, recurrence, prostate cancer, REL

\section{Introduction}

Prostate cancer (PCa), which is a heterogeneous-multifocal disease, ranks the most common cancer in men (1). The PCa incidence is growing, particularly in developed countries. One in six males in America will suffer from PCa in their lifetime, and every year there are $>900,000$ newly diagnosed PCa cases in the world (2). Genetic and environmental factors have been reported to be involved in the control of carcinogenesis and progression of $\mathrm{PCa}$ (3).

Over the past decades, recurrence of $\mathrm{PCa}$, which often demonstrates chemotherapy-resistant and androgen-independence, has drawn increasing attention. Great efforts have been made and considerable progress has been achieved to understand the molecular mechanism of the disease including epithelial-mesenchymal transition (EMT) (4), multidrug resistance gene expression (5), the mutation or amplification of androgen receptor and cancer stem cells (CSCs) or CSC-like cells (6). CSC model was first verified in acute myeloid leukemia (AML) in 1997 (7,8). This model supposed that cancers possessed hierarchical organization as the normal tissues did to a large degree and a small subset of tumor cells which were characterized by remarkable ability to generate new tumors constituted CSCs. Subsequently, CSCs have been identified in numerous human malignancies, including $\mathrm{PCa}$, liver cancer, pancreatic cancer, brain cancer and breast cancer (9-13). Consequently, it is important to identify the novel markers of CSCs, as more effective therapies might be available for patients with cancers.

As small non-coding RNAs consisting of 18-22 nucleotides, microRNAs (miRNAs) serve as important regulators in post-transcriptional regulation of target genes and mRNA silence by binding to the 3'-untranslated region (3'UTR), leading to inhibition or degradation of targeted mRNAs (14). Some miRNAs have been confirmed to be involved in numerous biological processes $(15,16)$. miRNAs have been shown to be involved in the control of recurrence of PCa (17), and have also been reported to be involved in regulating characteristics of CSCs (18). It has been previously shown that miR-574 is substantially downregulated in CSCs (19), and REL is believed to be a significant regulator of cancer cell proliferation (20). In this study, we confirmed the regulatory relationship between miR-574 and REL and verified that miR-574/REL signaling pathway is involved in the control of recurrence of PCa by modulating the expression of REL. 


\section{Materials and methods}

Study population and sample collection. In this study, we collected PCa samples with recurrence $(n=24)$ and without recurrence $(n=24)$ from Dongying People's Hospital of Shandong. Patients with a prostate-specific antigen (PSA) elevation of $>0.2 \mathrm{ng} / \mathrm{ml}$ after initially receiving radical prostatectomy (RP) or radiotherapy with curative intent is defined as biochemical recurrence. The study protocol was approved by the Ethics Committee of Dongying People's Hospital of Shandong. Written informed consents were obtained from all patients prior to the study.

Western blot analysis. Proteins were extracted from the cells using 1X Radioimmunoprecipitation Assay (RIPA) Lysis buffer (Upstate Biotechnology, Lake Placid, NY, USA) and the protein level was determined using protein assay reagents according to standard protocols (Bio-Rad Laboratories, Hercules, CA, USA). Western blot analysis was performed to assess protein expression. Briefly, $25 \mu \mathrm{g}$ of total protein was loaded on Life Technologies NuPAGE ${ }^{\circledR} 4-12 \%$ Bis-Tris gel (Thermo Fisher Scientific) and electrophoresed. After transfering to a pure nitrocellulose membrane (Bio-Rad Laboratories), we blocked the membranes with Odyssey ${ }^{\circledR}$ blocking buffer (LI-COR Biosciences, Lincoln, NE, USA). The membranes were then incubated in primary antibodies buffer (Odyssey blocking buffer, $0.1 \%$ Tween- $20^{\circledR}$ ) overnight at $4{ }^{\circ} \mathrm{C}$. The primary antibodies, anti-REL and anti-actin, were purchased from Cell Signaling Technology, Inc. (Beverly, MA, USA). The following day, membranes were washed four times for 5 min in Tris-buffered saline and Tween-20 (TBST). Subsequently, membranes were incubated in secondary antibodies IRDye ${ }^{\circledR}$ 680LT goat anti-mouse $\operatorname{lgG}$ or anti-rabbit $\lg \mathrm{G}$ (Cell Signaling Technology, Inc.) plus Odyssey blocking buffer and $0.1 \%$ Tween-20 at 1:20,000 dilution for $1 \mathrm{~h}$.

RNA isolation and real-time PCR. We extracted total RNA from PC-3 cells or tissue samples using High Pure Isolation kit in accordance with the manufacturer's instructions (Roche Life Science, West Sussex, UK). The miRNA Q-PCR detection kit (GeneCopoeia) was employed to quantify miR-574 level according to the manufacturer's instructions. Briefly, the protocol was conducted for 35 cycles at $95^{\circ} \mathrm{C}$ for $5 \mathrm{~min}$, $95^{\circ} \mathrm{C}$ for $10 \mathrm{sec}$, and $55^{\circ} \mathrm{C}$ for $10 \mathrm{sec}$. In total, 50 cycles were performed. The PCR amplification for the quantification of the miR-574 or REL and U6 was performed using TaqMan miRNA Reverse Transcription kit (Applied Biosystems, Foster City, CA, USA) according to the manufacturer's instructions. Primer sets for miR-574 or REL were designed using Primer3 software version 1.0 (Whitehead Institute for Biomedical Research, Cambridge, MA, USA). All the reactions were performed in triplicate and data were expressed as $2^{-\Delta \Delta C t}$.

Luciferase assay. The 3'UTR segment of miR-574 and REL siRNA was amplified and subcloned into the pmirGLO luciferase reporter vector (Promega). The corresponding mutant constructs were generated by mutating the seed regions of the miR-574 or REL siRNA binding sites. The cells $\left(3.5 \times 10^{4}\right)$ were seeded in triplicate in 24-well plates and cotransfected with wild-type (Wt)/mutant (Mt) 3'UTR vectors and miR-574 mimics or scramble control using Lipofectamine 2000. After $48 \mathrm{~h}$ of transfection, the cells were measured for luciferase activity on the Dual-Luciferase Reporter Assay System (Promega) according to the manufacturer's instructions. The firefly luciferase activities were normalized to Renilla luciferase activity. All experiments were repeated three times.

Cell proliferation assay. The viability was determined by 3-(4,5-dimethylthiazol-2-yl)-2,5-diphenyltetrazolium bromide (MTT) assay. The cells were seeded at a density of $2 \times 10^{3}$ cells/well in 96-well culture plates and incubated for $24 \mathrm{~h}$ at $37^{\circ} \mathrm{C}$ prior to transfection. The following day, cells were transfected with miR-574 or REL siRNA. After $48 \mathrm{~h}$, $20 \mathrm{ml}$ of MTT solution $(5 \mathrm{mg} / \mathrm{ml}$ in PBS) was added to each well. Samples were further incubated for $4 \mathrm{~h}$. The absorbance was read on a SPECTRAmax ${ }^{\circledR}$ microplate spectrophotometer (Molecular Devices, LLC, Sunnyvale, CA, USA) at a wavelength of $490 \mathrm{~nm}$. Experiments were carried out in triplicates.

CSC culture and transfection. Tumorsphere (prostatosphere) was cultured as described previously (18). Resulting tumorspheres were maintained at least 2 weeks with medium being changed at a 3-day interval. These prostatosphere cultures contained mainly cells with stemness markers and were considered as CSCs. miR-574 or REL siRNA mimics and scramble control mimics (GenePharma, Suzhou, China) were transfected in CSCs at a concentration of $50 \mathrm{nM}$ with Lipofectamine 2000 reagent (Invitrogen).

Apoptosis analysis. PC-3 cells were seeded in 6-well plates $\left(3.5 \times 10^{5}\right.$ cells/well) and transfected with mimics or inhibitors of miR-574 or NC as a control. Twenty-four hours later, $50 \mathrm{nmol} / 1$ of paclitaxel was added in media. After $48 \mathrm{~h}$ of incubation, cells were harvested and washed with cold PBS, stained with $5 \mu 1$ Annexin V-FITC and $10 \mu \mathrm{l}$ propidium iodide (PI) $(20 \mu \mathrm{g} / \mathrm{ml})$. The mixture was incubated at room temperature in the dark for $15 \mathrm{~min}$. Cell apoptosis was analyzed on the FACScan flow cytometer (Becton Dickinson, USA). Each experiment with triplicate samples was repeated three times.

Statistical analysis. The target genes of specific miRNAs were predicted using two prediction algorithms, TargetScan (http://www.targetscan.org/) and miRDB (http://mirdb. org/cgi-bin/search.cgi). The t-test (two groups) or one-way ANOVA (three groups or more) was used for assessing the statistical significance of each differential expression analysis result. All statistical analysis was performed using SPSS 20.0 (IBM, Inc., Chicago, IL, USA). P $<0.05$ was considered significant.

\section{Results}

$R E L$ is the virtual target of miR-574-5p. miR-574-5p has been reported involved with many diseases such as colorectal cancer, liver metastasis and lung cancer. In order to understand the role of miR-574-5p in PCa recurrence, we used online miRNA target prediction tools to search the regulatory gene of miR-574-5p, and consequently identified CCNG2, CUL5, EZH1 and REL as the candidate target genes of miR-574-5p in prostate CSCs with the 'seed sequence' in the 3'UTR (Fig. 1). 


\begin{tabular}{|c|c|c|c|}
\hline hsa-miR-574-5p & 5'-UGAGUGUGUGUGUGUGAGUGUGU-3' & hsa-miR-574-5p & 5'-UGAGUGUGUGUGUGUGAGUGUGU-3' \\
\hline Wt-CCNG2 & 3'-T AA TTACC TGTCA CACTC AGGAT-5' & Mt-CCNG2 & 3'-T AA TTACC TGTUGGCUC AAGGAT-5' \\
\hline hsa-miR-574-5p & 5'-UGAGUGUGUGUGUGUGAGUGUGU-3' & hsa-miR-574-5p & $\begin{array}{l}\text { 5'-UGAGUGUGUGUGUGUGAGUGUGU-3' } \\
\left.\qquad \begin{array}{c}1 \\
\vdots\end{array}\right)\end{array}$ \\
\hline Wt-CUL5 & 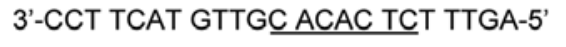 & Mt-CUL5 & 3'-CCT TCAT GTTG UGUCUCGT TTGA-5' \\
\hline hsa-miR-574-5p & 5'-UGAGUGUGUGUGUGUGAGUGUGU-3' & hsa-miR-574-5p & 5'-UGAGUGUGUGUGUGUGAGUGUGU-3' \\
\hline Wt-EZH1 & 3'-GGACATG CACA CACACTCACATGC-5' & Mt-EZH1 & 3'-GGACATG CACA UUGCGUUACATGC-5' \\
\hline
\end{tabular}

Figure 1. CCNG2, CUL5, EZH1 and REL as the candidate target genes of miR-574-5p in prostate cancer stem cells (CSCs) with the 'seed sequence' in the $3^{\prime}$ untranslated region ( $3^{\prime}$ UTR).

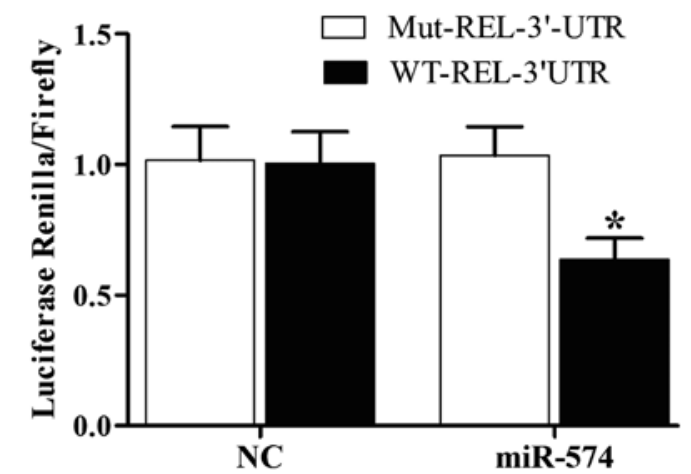

Figure 2. Luciferase activity reporter assay was conducted to verify REL as the direct target gene of miR-574. ${ }^{*} \mathrm{P}<0.05$.

Furthermore, to validate the regulatory relationship among miR-574-5p and CCNG2, CUL5, EZH1 and REL, we also conducted luciferase activity reporter assay in prostate CSCs, we can see the luciferase activity from the cells cotransfected with miR-574-5p and wild-type REL 3'UTR decreased significantly (Fig. 2), while cells cotransfected with miR-574-5p and CCNG2, CUL5, EZH1 3'UTR were comparable with scramble control (Fig. 2). The results confirmed that REL was a validated target of miR-574-5p in prostate CSCs. To further investigate the modulatory relationship between miR-574-5p and REL, we then analyzed the correlation between the expression level of miR-574-5p and REL mRNA among the tissues $(n=48)$, they showed negative regulatory relationship (Fig. 3).

Determination of expression patterns of miR-574 and REL in tissues with different groups. The tissues of two different groups (recurrence, $n=24$; non-recurrence, $n=24$ ) were used to further explore the impact on the interaction between miR-574 and REL 3'UTR. Using real-time PCR, we found that the expression of miR-574 decreased in recurrence groups (Fig. 4A) compared with non-recurrence group while the expression of REL mRNA (Fig. 4B) increased in the recurrence group compared with non-recurrence group; the expression of REL protein (Fig. C) was measured by densitometry analysis and we found it increased in the recurrence group compared with the normal group. To further validate the hypothesis of the negative regulatory relationship between miR-574-5p and REL, we investigated the mRNA/protein expression level of REL of prostate CSCs, by transfection with

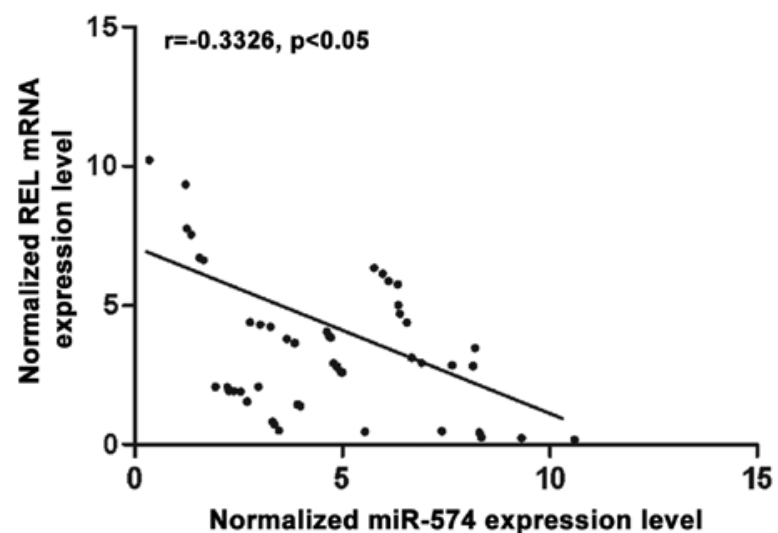

Figure 3. The correlation between the expression level of miR-574 and REL mRNA between intervertebral disc disease (IDD) and normal control (recurrence, $n=24$; non-recurrence, $n=24)$.

the prostate CSCs with scramble control, miR-574 mimics, REL siRNA and miR-574 inhibitors. As shown in Fig. 5, the REL protein (upper panel) and mRNA expression level (lower panel) of prostate CSCs treated with miR-574 mimics and REL siRNA were apparently lower than the scramble control, while cells treated miR-574 inhibitors were higher than the scramble control, validating the negative regulatory relationship between miR-574 and REL.

miR-574 and REL interfere with the viability in prostate CSCs. We also investigated the relative viability of prostate CSCs when transfected with scramble control, miR-574 mimics, REL siRNA and miR-574 inhibitors. Cells transfected with miR-574 inhibitors showed evident downregulated viability (Fig. 6A) when compared with the scramble controls, while cells transfected with miR-574 mimics and REL siRNA showed comparably lower viability, indicating miR-574 positively interfered with the viability of prostate CSCs, while REL negatively interfered with the viability of prostate CSCs.

miR-574 and REL interfere with apoptosis in prostate CSCs. We then investigated the relative apoptosis of prostate CSCs when transfected with scramble control, miR-574 mimics, REL siRNA and miR-574 inhibitors. When transfected with miR-574 mimics and REL siRNA, the number of surviving cells were more and the number of apoptotic cells were 

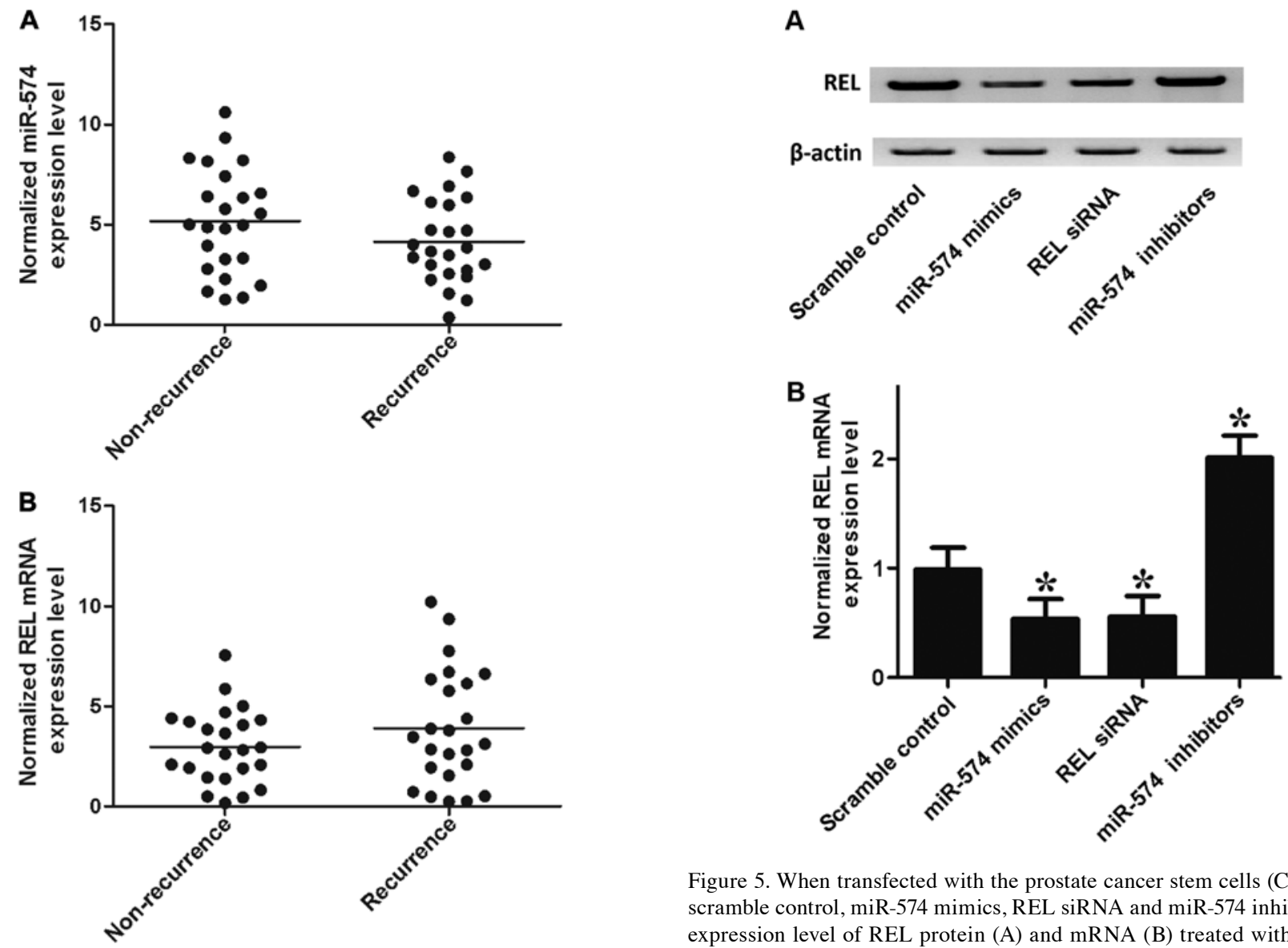

Figure 5. When transfected with the prostate cancer stem cells (CSCs) with scramble control, miR-574 mimics, REL siRNA and miR-574 inhibitors, the expression level of REL protein (A) and mRNA (B) treated with miR-574 mimics and REL siRNA decreased, while cells treated miR-574 inhibitors

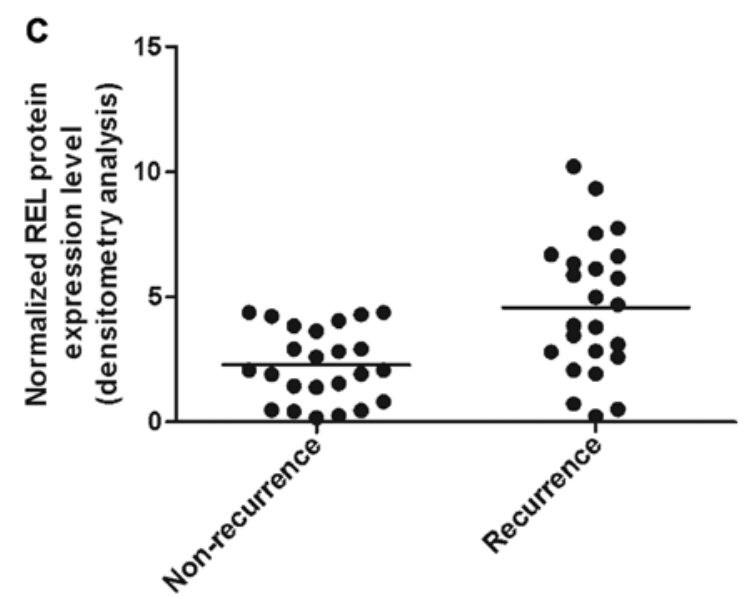
increased. ${ }^{*} \mathrm{P}<0.05$.

Figure 4. (A) The expression of miR-574 decreased, while the expressions of (B) REL mRNA and (C) protein increased, in recurrence group compared with normal control groups.

less than the scramble controls, while cells transfected with miR-574 inhibitors showed comparably less survival cells and more apoptotic cells. The results indicated that miR-574 inhibited apoptosis and REL accelerated apoptosis.

\section{Discussion}

CSCs have been proven to be present in numerous malignancies and it is believed that they are related to cancer recurrence, metastasis and resistance to chemo/radiotherapy (21). CSCs in $\mathrm{PCa}$ ranking the most common cancer in men worldwide

have been identified (22). Several features of PCa CSCs such as metastatic potential, functional characteristics, gene expression profiles and molecular signatures have been reported (23). Most data on CSCs were achieved from PCa cell lines, mainly from animal models and metastasis where the main bias was generated, leading to clinical objection of the findings. Some molecular markers for CSC including $\alpha 2 \beta 1$ integrin and CD 40 , CD44, and CD133 were identified by the above research (24). In this study, we found that he expression of miR-574 decreased in recurrence groups (Fig. 4A) compared with non-recurrence group while the expression of REL mRNA (Fig. 4B) increased in recurrence group compared with non-recurrence group; the expression of REL protein (Fig. 4C) was measured by densitometry analysis and we found that it increased in recurrence group compared with normal group.

Previous functional study indicated that overexpression of miR-574 led to inhibition of the invasion, migration, proliferation ability of gastric cancer cells (25). Downregulation of miR-574 in gastric cancer might be related to progression and development (25). Moreover, recent research considered that miR-574 served as tumor suppressor in bladder cancer (26). miRNAs exert a biological function by inducing target mRNA degradation, consequently, each miRNA can inhibit the production of a number of proteins (27). It is known that miR-574 suppressed the invasion, migration, proliferation ability and induced apoptosis of $\mathrm{BC}$ cells by targeting mRNAs of mesoderm development candidate 1 (MESDC1) directly (26). However, it remains unclear whether miR-574-3p 


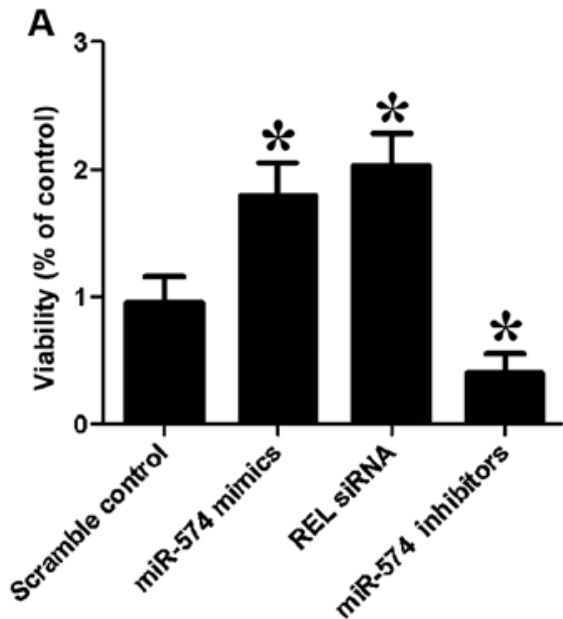

B
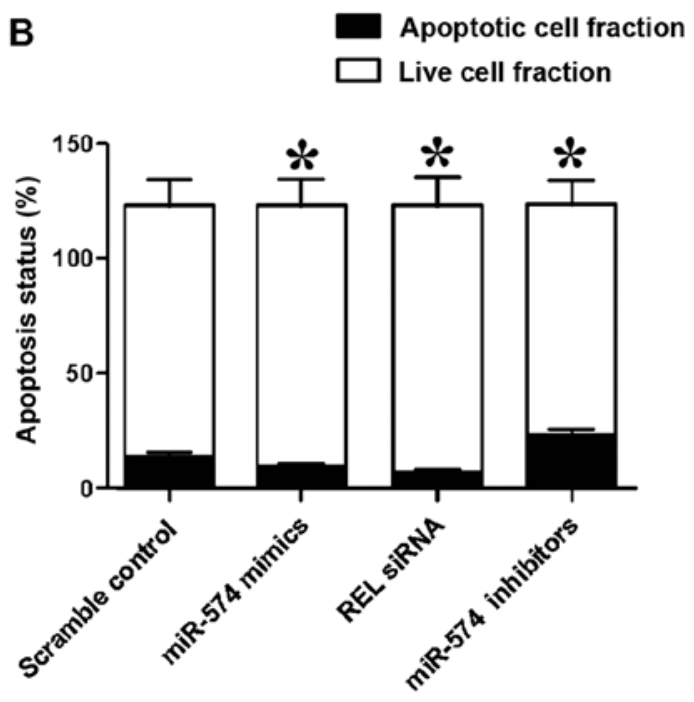

Figure 6. (A) Cells transfected with miR-574 inhibitors showed evidently downregulated viability, while cells transfected with miR-574 mimics and REL siRNA showed comparably higher viability. (B) Cells transfected with miR-574 mimics and REL siRNA, inhibited apoptosis while cells transfected with miR-124 inhibitors accelerated apoptosis. ${ }^{*} \mathrm{P}<0.05$.

exhibits the suppressive effect by targeting CUL2 directly in gastric cancer cells, which need further research to be proven. In this study, we conducted luciferase activity reporter assay in PCa cells, and found that the luciferase activity from the cells cotransfected with miR-574-5p and wild-type REL 3'UTR decreased significantly (Fig. 2), and then we analyzed the correlation between the expression level of miR-574-5p and REL mRNA in the tissues $(\mathrm{n}=48)$, the results showed negative regulatory relationship (Fig. 3). The results confirmed that REL was a validated target of miR-574-5p in prostate CSCs.

Currently, $\mathrm{PCa}$ can be diagnosed at the early stage, however, it remains hard to predict if it stays dormant or develops into a metastatic, advanced disease, which might result from the absence of clinically proven molecular markers predicting the progression of PCa. Numerous candidate proteins and genes are under investigation, however, few of them were established by multivariate analyses (28). It has been shown that REL, a factor of the NF- $\mathrm{KB}$ transcription factor family, served as an independent factor to predict the biochemical recurrence (29). Moreover, high levels of nuclear REL was detected in lymph node metastases by staining as well as in patients who suffered bone metastases (30). Therefore, it appears that REL participates in PCa progression while how other NF- $\mathrm{KB}$ family members function remains largely unknown. Encoded by the REL gene, REL is a unique member of NF- $\mathrm{KB}$ family. REL has a predominant expression in myeloid and lymphoid tissues, which might be result from unique regulators for activation of REL. I $\mathrm{B} \alpha$, inhibitor of NF- $\mathrm{kB}$, preferentially inhibits $\mathrm{p} 50 / \mathrm{p} 65$ dimers, whereas $\mathrm{p} 65 / \mathrm{REL}$ is controlled by $\mathrm{I} \kappa \mathrm{B} \varepsilon$ and the protease activities of MALT1 and the non-redundant regulator IкB $\beta$ induces activation of REL (31-35). Nuclear localization of REL was impaired by MALT1 inhibitors which also exhibited selective activity against ABC-DLBCL in vivo (36). Additionally, it has been found that activation of 50/c-REL and degradation of I $\mathrm{B} \alpha$ in $\mathrm{B}$-cells (37) were related to a novel signal pathway which was dependent on IкB kinase (IKK) and independent of proteasome. The stimuli for this pathway was different from that of the non-canonical NF-kB pathway. But there is little knowledge on the upstream stimuli for activation of $\mathrm{NF}-\kappa \mathrm{B}$, for example signaling differentially regulatingREL, mitogen-activated protein kinases (MAPK), Toll-like receptors (TLR), tumor-necrosis factor (TNF) receptors, T-cell receptors (TCR), B-cell receptors (BCR) and other NF- $\kappa \mathrm{B}$ subunits (38). In this study, we found that the cells transfected with miR-574 inhibitors showed evidently downregulated viability (Fig. 6A) when compared with the scramble controls, while cells transfected with miR-574 mimics and REL siRNA showed comparably lower viability, indicating miR-574 positively interfered with the viability of prostate CSCs, while REL negatively interfered with the viability of prostate CSCs. Furthermore, we investigated the relative apoptosis of prostate CSCs when transfected with scramble control, miR-574 mimics, REL siRNA and miR-574 inhibitors. When transfected with miR-574 mimics and REL siRNA, the number of survival cells were more and the number of apoptotic cells were less than the scramble controls, while cells transfected with miR-574 inhibitors showed comparably less survival cells and more apoptotic cells. The results indicated miR-574 inhibited apoptosis and REL accelerated apoptosis.

Taken together, the findings indicated that REL is a direct target of miR-574 in prostate CSCs, and miR-574 might be a novel prognostic and therapeutic target in the management of PCa recurrence.

\section{References}

1. Yamamoto S, Kawakami S, Yonese J, Fujii Y, Urakami S, Masuda H, Numao N, Ishikawa Y, Kohno A and Fukui I: Long-term oncological outcome and risk stratification in men with high-risk prostate cancer treated with radical prostatectomy. Jpn J Clin Oncol 42: 541-547, 2012.

2. Jemal A, Bray F, Center MM, Ferlay J, Ward E and Forman D: Global cancer statistics. CA Cancer J Clin 61: 69-90, 2011.

3. Utomo NB, Mochtar CA and Umbas R: Primary hormonal treatment in localized and locally advanced prostate cancer: Effectiveness and survival predictive factors. Acta Med Indones 44: 10-15, 2012.

4. Gravdal K, Halvorsen OJ, Haukaas SA and Akslen LA: A switch from E-cadherin to $\mathrm{N}$-cadherin expression indicates epithelial to mesenchymal transition and is of strong and independent importance for the progress of prostate cancer. Clin Cancer Res 13: 7003-7011, 2007. 
5. Theyer G, Schirmböck M, Thalhammer T, Sherwood ER, Baumgartner G and Hamilton G: Role of the MDR-1-encoded multiple drug resistance phenotype in prostate cancer cell lines. J Urol 150: 1544-1547, 1993.

6. Linja MJ, Savinainen KJ, Saramäki OR, Tammela TL, Vessella RL and Visakorpi T: Amplification and overexpression of androgen receptor gene in hormone-refractory prostate cancer. Cancer Res 61: 3550-3555, 2001.

7. Mackillop WJ, Ciampi A, Till JE and Buick RN: A stem cell model of human tumor growth: Implications for tumor cell clonogenic assays. J Natl Cancer Inst 70: 9-16, 1983.

8. Bonnet D and Dick JE: Human acute myeloid leukemia is organized as a hierarchy that originates from a primitive hematopoietic cell. Nat Med 3: 730-737, 1997.

9. Collins AT, Berry PA, Hyde C, Stower MJ and Maitland NJ: Prospective identification of tumorigenic prostate cancer stem cells. Cancer Res 65: 10946-10951, 2005.

10. Yang ZF, Ho DW, Ng MN, Lau CK, Yu WC, Ngai P, Chu PW, Lam CT, Poon RT and Fan ST: Significance of CD90 ${ }^{+}$cancer stem cells in human liver cancer. Cancer Cell 13: 153-166, 2008.

11. Li C, Heidt DG, Dalerba P, Burant CF, Zhang L, Adsay V, Wicha M, Clarke MF and Simeone DM: Identification of pancreatic cancer stem cells. Cancer Res 67: 1030-1037, 2007.

12. Singh SK, Hawkins C, Clarke ID, Squire JA, Bayani J, Hide T, Henkelman RM, Cusimano MD and Dirks PB: Identification of human brain tumour initiating cells. Nature 432: 396-401, 2004.

13. Al-Hajj M, Wicha MS, Benito-Hernandez A, Morrison SJ and Clarke MF: Prospective identification of tumorigenic breast cancer cells. Proc Natl Acad Sci USA 100: 3983-3988, 2003.

14. Bartel DP: MicroRNAs: Genomics, biogenesis, mechanism, and function. Cell 116: 281-297, 2004

15. Schratt GM, Tuebing F, Nigh EA, Kane CG, Sabatini ME, Kiebler $\mathrm{M}$ and Greenberg ME: A brain-specific microRNA regulates dendritic spine development. Nature 439: 283-289, 2006.

16. Mehler MF and Mattick JS: Non-coding RNAs in the nervous system. J Physiol 575: 333-341, 2006.

17. Amankwah EK, Anegbe E, Park H, Pow-Sang J, Hakam A and Park JY: miR-21, miR-221 and miR-222 expression and prostate cancer recurrence among obese and non-obese cases. Asian J Androl 15: 226-230, 2013.

18. Liu C, Kelnar K, Liu B, Chen X, Calhoun-Davis T, Li H, Patrawala L, Yan H, Jeter C, Honorio S, et al: The microRNA miR-34a inhibits prostate cancer stem cells and metastasis by directly repressing CD44. Nat Med 17: 211-215, 2011.

19. Rane JK, Scaravilli M, Ylipää A, Pellacani D, Mann VM, Simms MS, Nykter M, Collins AT, Visakorpi T and Maitland NJ: MicroRNA expression profile of primary prostate cancer stem cells as a source of biomarkers and therapeutic targets. Eur Urol 67: 7-10, 2015.

20. Lessard L, Bégin LR, Gleave ME, Mes-Masson AM and Saad F: Nuclear localisation of nuclear factor-kappaB transcription factors in prostate cancer: An immunohistochemical study. Br J Cancer 93: 1019-1023, 2005.

21. Nagler C, Zänker KS and Dittmar T: Cell fusion, drug resistance and recurrence CSCs. Adv Exp Med Biol 714: 173-182, 2011.

22. Tu SM and Lin SH: Prostate cancer stem cells. Clin Genitourin Cancer 10: 69-76, 2012

23. Tirino V, Desiderio V, Paino F, De Rosa A, Papaccio F, La Noce M, Laino L, De Francesco F and Papaccio G: Cancer stem cells in solid tumors: An overview and new approaches for their isolation and characterization. FASEB J 27: 13-24, 2013.
24. Zhang Z, Filho MS and Nör JE: The biology of head and neck cancer stem cells. Oral Oncol 48: 1-9, 2012.

25. Su Y, Ni Z, Wang G, Cui J, Wei C, Wang J, Yang Q, Xu Y and Li F: Aberrant expression of microRNAs in gastric cancer and biological significance of miR-574-3p. Int Immunopharmacol 13: 468-475, 2012

26. Tatarano S, Chiyomaru T, Kawakami K, Enokida H, Yoshino H, Hidaka H, Nohata N, Yamasaki T, Gotanda T, Tachiwada T, et al: Novel oncogenic function of mesoderm development candidate 1 and its regulation by miR-574-3p in bladder cancer cell lines. Int J Oncol 40: 951-959, 2012.

27. Chekulaeva M and Filipowicz W: Mechanisms of miRNA-mediated post-transcriptional regulation in animal cells. Curr Opin Cell Biol 21: 452-460, 2009.

28. Tricoli JV, Schoenfeldt M and Conley BA: Detection of prostate cancer and predicting progression: Current and future diagnostic markers. Clin Cancer Res 10: 3943-3953, 2004.

29. Ross JS, Kallakury BV, Sheehan CE, Fisher HA, Kaufman RP Jr, Kaur P, Gray K and Stringer B: Expression of nuclear factor-kappa B and I kappa B alpha proteins in prostatic adenocarcinomas: Correlation of nuclear factor-kappa B immunoreactivity with disease recurrence. Clin Cancer Res 10: 2466-2472, 2004.

30. Ismail HA, Lessard L, Mes-Masson AM and Saad F: Expression of NF-kappaB in prostate cancer lymph node metastases. Prostate 58: 308-313, 2004.

31. Gilmore TD and Gerondakis S: The c-Rel transcription factor in development and disease. Genes Cancer 2: 695-711, 2011.

32. Clark JM, Aleksiyadis K, Martin A, McNamee K, Tharmalingam T, Williams RO, Mémet S and Cope AP: Inhibitor of kappa B epsilon $(\mathrm{I} \kappa \mathrm{B} \varepsilon)$ is a non-redundant regulator of c-Rel-dependent gene expression in murine T and B cells. PLoS One 6: e24504, 2011

33. Alves BN, Tsui R, Almaden J, Shokhirev MN, Davis-Turak J, Fujimoto J, Birnbaum H, Ponomarenko J and Hoffmann A: IкBe is a key regulator of $\mathrm{B}$ cell expansion by providing negative feedback on cRel and RelA in a stimulus-specific manner. J Immunol 192: 3121-3132, 2014.

34. Refaat A, Zhou Y, Suzuki S, Takasaki I, Koizumi K, Yamaoka S, Tabuchi Y, Saiki I and Sakurai H: Distinct roles of transforming growth factor-beta-activated kinase 1 (TAK1)-c-Rel and interferon regulatory factor 4 (IRF4) pathways in human T cell lymphotropic virus 1-transformed $\mathrm{T}$ helper 17 cells producing interleukin-9. J Biol Chem 286: 21092-21099, 2011.

35. Thome M, Charton JE, Pelzer C and Hailfinger S: Antigen receptor signaling to NF-kappaB via CARMA1, BCL10, and MALT1. Cold Spring Harb Perspect Biol 2: a003004, 2010.

36. Fontan L, Yang C, Kabaleeswaran V, Volpon L, Osborne MJ, Beltran E, Garcia M, Cerchietti L, Shaknovich R, Yang SN, et al: MALT1 small molecule inhibitors specifically suppress ABC-DLBCL in vitro and in vivo. Cancer Cell 22: 812-824, 2012.

37. O'Connor S, Shumway SD, Amanna IJ, Hayes CE and Miyamoto S: Regulation of constitutive p50/c-Rel activity via proteasome inhibitor-resistant IkappaBalpha degradation in B cells. Mol Cell Biol 24: 4895-4908, 2004.

38. Li Q and Verma IM: NF-kappaB regulation in the immune system. Nat Rev Immunol 2: 725-734, 2002. 